Колиекция гуманитарных исследований. Электронный научный журнал. The Collection of Humanitarian Researches. Electronic scientific journal

peer-reviewed • open access journal

DOI: $10.21626 / \mathrm{j}-\mathrm{chr} / 2021-4(29) / 14$

Педагогические науки

УДК: 37.014.6:376(470+571)

\title{
Проблема оценки качества образовательного процесса в Российской Федерации в условиях ИНКдЮзИИ
}

\section{(C) Р.А. Дормидонтов, В.К. Елисеев, А.И. Меремьянина}

Дормидонтов Р.А. - кандидат педагогических наук, доцент кафедры психологии, педагогики и специального образования Аипецкого государственного педагогического университета им. П.П. Семенова-Тян-

$104 \quad$ E-mail: dormi1976@mail.ru

Едисеев В.К. - доктор педагогических наук, профессор кафедры психологии, педагогики и специального образования Дипецкого государственного педагогического университета им. П.П. Семенова-Тян-Шанского E-mail: elvk56 @mail.ru

Меремьянина А.И. - кандидат педагогических наук, доцент кафедры психологии, педагогики и специального образования Аипецкого государственного педагогического университета им. П.П. Семенова-ТянШанского

E-mail: alsandra55@mail.ru

Адрес: 398050, г. Липецк, ул. Плеханова, 32, Российская Федерация

№4 (29) 2021 www.j-chr.com

\section{АННОТАЦИЯ}

В статье представлен анализ систем оценки качества реализации инклюзивного образования в общеобразовательных организациях Российской Федерации.

Ключевые слова: системы оценки качества инклюзивного образования, критерии ка-чества, структурные и психологопедагогические компоненты инклюзивного образования. 
Исследование выполнено при финансовой поддержке Министерства просвещения РФ в рамках исподнения государственного задания на НИР, научный проект: «Психология и пе-дагогика инклюзивного образования: оценка качества инклюзивного образования в общеоб-разовательных организациях Российской Федерации», № соглашения: 073-03-2021-017/2 от 21.072021

Научные исследования российских ученых, посвященные проблеме мониторинга и оценки качества условий для обучающихся с ОВ3 и инвалидностью, можно условно разделить на две большие группы: оценка качества предоставляемых условий реализации инклюзивного образования (Т. Г. Богданова, Н. М. Назарова [4], Д. С. Ильина [6], А. В. Ильина, Ю. Г. Маковецкая, О. Н. Тверская и др.) и анализ динамики индикаторов качества инклюзии (С. В. Алехина, Ю. В. Мельник, Е. В. Самсонова, А. Ю. Шеманов [1, 3], Н. А. Мёдова [7], Л. М. Низова, М. И. Данилова [8], Т. Л. Чепель, Т. П. Абакирова, А. Ю.Шеманов и др.). В большинстве работ (С. В. Алехина, Д. С. Ильина, 0. Г. Петрович, Н. А. Ряписов, А. Г. Ряписова, Т. Л. Чепель, Т. П. Абакирова, С. В. Самуйленко), посвященных проблеме оценки качества инклюзивного образования, в качестве инструмента оценки качества чаще всего указывается именно мониторинг. В современных педагогических условиях мониторинг рассматривается как один из наиболее эффективных инструментов оценки качества инклюзивного образования, с помощью которого представляется возможным выявлять и анализировать изменения в инклюзивном процессе на всех уровня образования с учетом различных категорий детей с 0B3 и детей-инвалидов, форм инклюзии.

В условиях муниципальной образовательной системы, критериями и показателями эффективности реализации предложенной модели инклюзивного образования могут выступать: консультативно-организационно-методическое обеспечение инклюзивного образования; наличие двухуровневой системы с базовым учреждением в качестве ресурсного центра, подготовка учителей к работе в инклюзивном образовании посредством организации курсов повышения квалификации и переподготовки для профессорско-преподавательского состава и школьных учителей, удовлетворение образовательных потребностей детей с 0B3 и их родителей, вариативность получения образования, повышение инклюзивной компетентности работников образования [7].

Объектами мониторинга нередко выступает качество инфраструктурных компонентов инклюзивного образования, как то: нормативно-правовая база и специальное программно-методическое обеспечение, направленные на наибо-лее эффективную интеграцию детей с ОВ3 в образовательное и социокультур-ное пространство общеобразовательной школы. Другим качественным компо-нентом выступает содержание деятельности всех специалистов, вовлеченных в процесс инклюзии. Наконец, невозможно достигнуть наиболее оптимальных качественных результатов без наличия системы диагностических и контрольно-оценочных мероприятий, позволяющих своевременно выявить трудности обучающихся с ограниченными возможностями здоровья и педагогов, работающих с ними, а также проследить положительную динамику инклюзивного процесса в образовательной организации.

Система оценки качества инклюзив-
№4 (29) 2021 www.j-chr.com

ТЕМАТИЧЕСКИЙ ВЫПУСК, ПОСВЯЩЕННЫЙ ЗО-ЛЕТИЮ СОЦИАЛЬНОЙ РАБОТЫ В РОССИИ

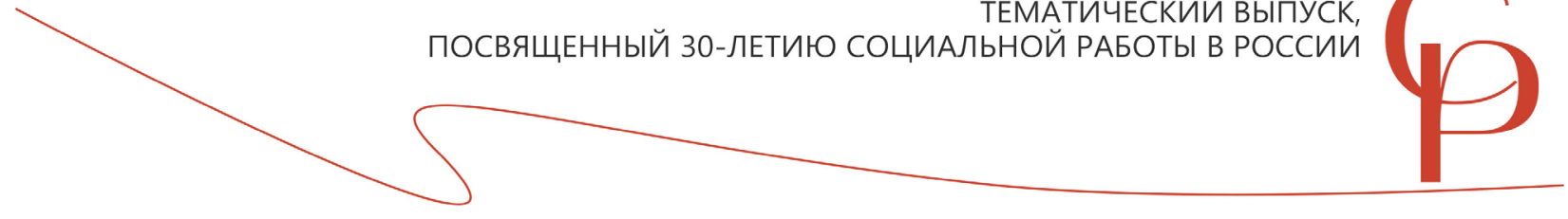


ного процесса в образовательной организации, по мнению многих российских ученых (С. В. Алехина, Т. Г. Богданова, Н. М., Ильина, О.Г., Ю. В. Мельник, Назарова, Д. С. Петрович, Е. В. Самсонова, А. Ю. Шеманов, Д. Е. Шевелева и др.), направлена на выявление уровней эффективности достижения целей при планировании результатов интеграции детей с 0B3 в массовую школу: насколько разнообразны формы их реализации с применением современных психолого-педагогических технологий, насколько высок профессиональный уровень всех участников образовательного процесса.

В некоторых субъектах Российской Федерации введена процедура оценки качества адаптированных основных образовательных программ (АООП) в соответствии с требованиями федеральных государственных образовательных стандартов начального общего образования обучающихся с 0B3 $[6,8]$. Так, в общеобразовательных организациях Челябинской области был проведен мониторинг оценки качества инклюзивного образования с учетом всех категорий нарушения здоровья обучающихся. В результате было выявлено качество ресурсного, кадрового, финансового и материально-технического обеспечения АООП и разработан инвариантный оценочный механизм, позволяющий наиболее эффективно отслеживать и оценивать условия их реализации [6]. Заслуживает внимание опыт Новосибирской области, в котором акцент

\section{ЛИТЕРАТУРА}

1. Алехина С.В. К вопросу оценки инклюзивного процесса в образователь-

№4 (29) 2021 www.j-chr.com ной организации: пилотажное исследование / С.В. Алехина, Ю.В. Мельник, Е.В. Самсонова, А.Ю. Шеманов // в реализации инклюзивного образования в регионе сделан именно на оценке его качества. Целью работы созданной в Новосибирском государственном педагогическом университете международной научной школы «Мониторинг эффективности инклюзивной практики» выступила разработка методического и критериального аппарата контроля эффективности образовательного процесса в условиях инклюзии. В исследовании, проведенном в рамках указанной выше школы, делается акцент на комплексный характер оценки качества результатов инклюзивного процесса, подразумевающей независимую внешнюю оценку в форме государственной итоговой аттестации (государственный выпускной экзамен), и внутреннюю оценку (текущий контроль и промежуточная аттестация), что позволяет включить в оценочный процесс потребителей образовательных услуг [11].

Таким образом, стоит констатировать, что в настоящее время в России в качество критериев оценки эффективности инклюзивного образования используется, в основном, качество инфраструктурных компонентов инклюзивного образования: нормативно-правовая база и программно-методическое обеспечение и др. При этом целостная система оценки качества инклюзии, базирующая на научно обоснованных психолого-педагогических критериях, до настоящего времени не сложилась. 
С.В. Алехина, Ю.В. Мельник, Е.В. Самсонова, А.Ю. Шеманов // Клиническая и специальная психология. - 2020. - Том. 9. - № 2. - С. 62-78. - Режим доступа: Портал психологических изда-ний PsyJournals.ru https://psyjournals.ru/psyclin/2020/n2/ Alehina_et_al_full.shtml

3.АлехинаС.В.0мониторингеинклюзивного процесса в образовании / С.В. Алехина // Материалы научно-практической конференции «Инклюзивное образование: методология, практика, технология» (ред. кол. С.В. Алехина и др.) - М.: МГППУ, 2011. $-244 \mathrm{c}$.

4. Богданова Т.Г. Эвалюация как инструмент управления качеством инклюзивных процессов в образовании /Т.Г. Богданова, Н.М. Назарова// Специ-альное образование. - 2020. - № 3. - С. 24-39

5. Вакорина, Л.Ю. Инклюзивное образование в России: механизмы управления и повышения эффективности: дис. ... канд. социологических наук: 22.00.08 / Вакорина Людмила Юрьевна. - М., 2019. $221 \mathrm{c.}$

6. Ильина Д.С. Мониторинг ФГОС ОВЗ как оценочная процедура ресурсного обеспечения реализации адаптированных образовательных программ /Д.С. Ильина// Научно-методическое обеспечение оценки качества образования. - 2019. - № 3 (8). - C. 28-32.

7. Мёдова Н.А. Модель инклюзивного образования в условиях муниципальной образовательной системы. 13.00.01 Общая педагогика, история педа-гогики и образования: автореф. дис. на соискание ученой степени канд. пед. наук / Н.А. Мёдова. - Томск, 2013.

8. Низова Л.М. Инклюзивное образование как форма социализации инвалидов (на примере Республики Марий Эл) / Л.М. Низова, М.И.Данилова // 0б-разовательная политика. - 2017. - № 1 (75). - С. 102-109.

9. Петрович 0.Г. Система мониторинговых исследований условий обучения лиц с ОВЗ и инвалидностью: опыт института развития образования / О.Г. Петрович // Вестник Саратовского областного института развития образования. - 2020. - № 1 (21). - С. 33-41

10. Реализация адаптированных образовательных программ основного общего образования для детей с $0 \mathrm{~B} 3$, создание условий для полноценной реализации в общеобразовательных организациях инклюзивного образования: методические рекомендации / A. В. Ильина, Ю.Г. Маковецкая, О.Н. Тверская, И.Л. Дубровина. - Челябинск: ЧИППКРО, 2019. - 96 с.

11. Ряписов Н.А. Мониторинг эффективности инклюзивной практики / Н.А. Ряписов, А.Г. Ряписова // Вестник Новосибирского государственного педагогического университета. - 2016. - № 1 (29). - C. $7-19$
№4 (29) 2021

www.j-chr.com

ТЕМАТИЧЕСКИЙ ВЫПУСК,

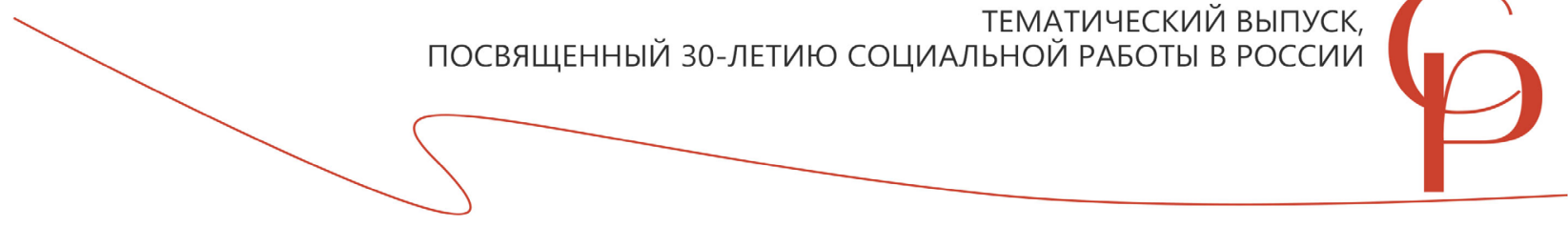




\section{THE PROBLEM OF ASSESSING THE QUALITY OF THE EDUCATIONAL PROCESS IN THE RUSSIAN FEDERATION IN THE CONDITIONS OF INCLUSION}

\section{(C) Roman A. Dormidontov, Vladimir K. Eliseev, Alexandra I. Meremyanina}

Roman A. Dormidontov - Candidate of Pedagogical Sciences, Associate Professor, Lipetsk State Pedagogical P. Semenov-Tyan-Shanskij University E-mail: E-mail: dormi1976@mail.ru

Vladimir K. Eliseev - PhD in Pedagogy, Full Professor, Lipetsk State Pedagogical P. Semenov-Tyan-Shanskij University

E-mail: elvk56@mail.ru

Alexandra I. Meremyanina - Candidate of Pedagogical Sciences, Associate Professor, Lipetsk State Pedagogical P. Semenov-Tyan-Shanskij University E-mail: alsandra55@mail.ru

Address: 398050, Lipetsk, Plekhanova str., 32, Russian Federation

№4 (29) 2021

www.j-chr.com

\section{ABSTRACT}

The article presents an analysis of systems for assessing the quality of the implementation of inclusive education in general education organizations of the Russian Federation.

Keywords: systems for assessing the quality of inclusive education, quality criteria, structural and psychological-pedagogical components of inclusive education. 


\section{REFERENCES}

1. Alekhina S.V. K voprosu ocenki inklyuzivnogo processa v obrazovatel'-noj organizacii: pilotazhnoe issledovanie / S.V. Alekhina, YU.V. Mel'nik, E.V. Samsonova, A.YU. SHemanov // Psihologo-pedagogicheskie issledovaniya. - 2019. - Tom 11. - № 4. - S. 121-132.

2. Alekhina S.V. Ekspertnaya ocenka parametrov inklyuzivnogo processa v obrazovanii [Elektronnyj resurs] / S.V. Alekhina, YU.V. Mel'nik, E.V. Samso-nova, A.YU. SHemanov // Klinicheskaya i special'naya psihologiya. - 2020. - Tom. 9. - № 2. - S. 62-78. - Rezhim dostupa: Portal psihologicheskih izda-nij PsyJournals.ru https://psyjournals.ru/psyclin/2020/n2/Alehina_et_al_full.shtml 3. Alekhina S.V. 0 monitoringe inklyuzivnogo processa v obrazovanii / S.V. Alekhina // Materialy nauchno-prakticheskoj konferencii «Inklyuzivnoe obrazovanie: metodologiya, praktika, tekhnologiya» (red. kol. S.V. Alekhina i dr.) - M.: MGPPU, 2011. - 244 s.

4. Bogdanova T.G. Evalyuaciya kak instrument upravleniya kachestvom in-klyuzivnyh processov v obrazovanii /T.G. Bogdanova, N.M. Nazarova// Speci-al'noe obrazovanie. 2020. - № 3. - S. 24-39

5. Vakorina, L.YU. Inklyuzivnoe obrazovanie v Rossii: mekhanizmy uprav-leniya i povysheniya effektivnosti: dis. ... kand. sociologicheskih nauk: 22.00.08 / Vakorina Lyudmila YUr'evna. - M., 2019. - $221 \mathrm{~s}$.

6. Il'ina D.S. Monitoring FGOS OVZ kak ocenochnaya procedura resurs-nogo obespecheniya realizacii adaptirovannyh obrazovatel'nyh pro gramm /D.S. Il'ina// Nauchno-metodicheskoe obespechenie ocenki kachestva obrazovaniya. - 2019. - № 3 (8). - S. 28-32.

7. Myodova N.A. Model' inklyuzivnogo obrazovaniya $\mathrm{v}$ usloviyah munici-pal'noj obrazovatel'noj sistemy. 13.00.01 - 0bshchaya pedagogika, istoriya peda-gogiki i obrazovaniya: avtoref. dis. na soiskanie uchenoj stepeni kand. ped. nauk / N.A. Myodova. Tomsk, 2013.

8. Nizova L.M. Inklyuzivnoe obrazovanie kak forma socializacii inva-lidov (na primere Respubliki Marij El) / L.M. Nizova, M.I. Danilova // 0b-razovatel'naya politika. 2017. - № 1 (75). - S. 102-109.

9. Petrovich 0.6. Sistema monitoringovyh issledovanij uslovij obuche-niya lic s OVZ i invalidnost'yu: opyt instituta razvitiya obrazovaniya / 0.G. Petrovich // Vestnik Saratovskogo oblastnogo instituta razvitiya obrazovaniya. - 2020. - № 1 (21). - S. 33-41

10. Realizaciya adaptirovannyh obrazovatel'nyh programm osnovnogo obshchego obrazovaniya dlya detej s OVZ, sozdanie uslovij dlya polnocennoj realizacii v obshcheobrazovatel'nyh organizaciyah inklyuzivnogo obrazovaniya: metodicheskie rekomendacii / A. V. Il'ina, YU.G. Makoveckaya, O.N. Tverskaya, I.L. Dubrovina. - CHelyabinsk: CHIPPKR0, 2019. - 96 s.

11. Ryapisov N.A. Monitoring effektivnosti inklyuzivnoj praktiki / N.A. Ryapisov, A.G. Ryapisova // Vestnik Novosibirskogo gosudarstvennogo pedagogi-cheskogo universiteta. - 2016. - № 1 (29). - S. 7-19

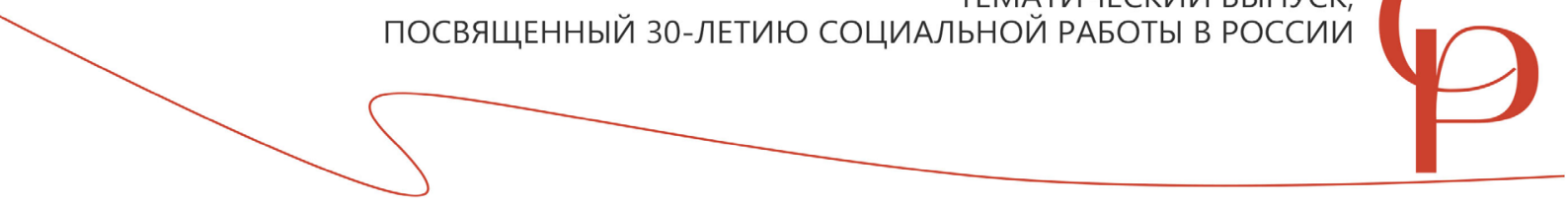

